\title{
Role of Oxidative DNA Damage and Antioxidative Enzymatic Defence Systems in Human Aging
}

\author{
Manuela Dittmar ${ }^{1, *}$, Melanie Knuth ${ }^{2}$, Marc Beineke $^{3}$ and Bernd Epe ${ }^{4}$ \\ ${ }^{I}$ Department of Human Biology, Zoological Institute, University of Kiel, Germany; ${ }^{2}$ Institute of Anthropology, Univer- \\ sity of Mainz, Germany; ${ }^{3}$ Bioscientia Laboratories, Ingelheim, Germany and ${ }^{4}$ Institute of Pharmacy, University of \\ Mainz, Germany
}

\begin{abstract}
Oxidative stress is regarded as a main causal factor for natural aging. This study tested the hypothesis that healthy elderly people show higher oxidative DNA damage levels and lower antioxidative enzymatic defense capacities than younger ones. In a cross-sectional study, blood samples of 20 older (62-79 years) and 20 younger adults (24-28 years) were compared with respect to oxidative DNA damage in lymphocytes (alkaline elution), oxidative status (serum peroxides), activities of superoxide dismutase (SOD) and glutathione peroxidase (GPx) and concentrations of total glutathione. In accordance with our hypothesis, elderly males showed a tendency towards higher levels of oxidative DNA damage (single strand breaks). SOD activity inversely correlated with the amount of DNA damage (single-strand breaks and Fpg-sensitive modifications). Oxidative status was increased in older men and negatively correlated with glutathione concentrations. GPx activity was elevated and the SOD/GPx ratio lowered in older males. Subjects with lowered SOD/GPx ratio showed increased oxidative DNA damage. The results indicate age-related changes in the balance between first step (SOD) and second step (GPx) of the enzymatic antioxidant defense system. They support the assumption that a biological optimum between antioxidative enzymes might be more important than their absolute activities.
\end{abstract}

Key Words: Aging, oxidative DNA damage, oxidative status, antioxidative enzymes, superoxide dismutase, glutathione peroxidase, glutathione.

\section{INTRODUCTION}

Different hypotheses have been proposed to explain the aging processes in humans. Among the related theories, the most advanced is the oxidative damage theory, which has been developed from the free radical theory of Harman [1, 2]. It considers oxidative stress as main causal factor for natural aging and is based on the high reactivity of reactive oxygen species (ROS), which are ubiquitously generated byproducts of the oxygen metabolism in living beings [3-5]. An imbalance between oxidative and reductive processes in favor of oxidative ones is called oxidative stress and supposed to result in extensive oxidative damage to nucleic acids, proteins and lipids [6-8]. These damaged molecules perturb cellular homeostasis, reducing more and more functionability and life span of cells and finally of organs [9]. Studies in animals indeed have indicated that oxidative damage accumulates during life in proteins, lipids and DNA [10]. In humans, an excess of ROS has been made responsible for premature aging and the development of atherosclerosis and cancer [11-13]. Increased oxidative stress has also been found in patients with chronic renal failure [14].

Oxidative stress is caused in humans by various pathophysiological mechanisms, in particular by the increased production of ROS during inflammatory processes and by various environmental factors (ionizing radiation, nicotine,

\footnotetext{
*Address correspondence to this author at the Department of Human Biology, Zoological Institute, Christian-Albrechts-University, 24118-Kiel, Germany; Tel: +49-(0)431-880 4357; Fax: +49-(0)431-880 2795;

E-mail: mdittmar@zoologie.uni-kiel.de
}

alcohol, unbalanced diet, etc.). Protective enzymatic and non-enzymatic antioxidant defense mechanisms reduce oxidative stress by degradating ROS. Major intracellular antioxidative enzymes are the superoxide dismutase (SOD), catalase (CAT), and glutathione peroxidase (GPx). They act in two steps: firstly, SOD converts the highly active superoxide radicals $\left(\mathrm{O}_{2}{ }^{-}\right)$into hydrogen peroxide $\left(\mathrm{H}_{2} \mathrm{O}_{2}\right)$ and oxygen $\left(\mathrm{O}_{2}\right)$. Afterwards, CAT and GPx independently convert $\mathrm{H}_{2} \mathrm{O}_{2}$ to water and oxygen [15]. Glutathione (GSH) is not only a cofactor for GPx, but can also react as a direct scavenger of ROS [16]. On the non-enzymatic level, also vitamins (vita$\min C$, vitamin $E$ and $\beta$-carotene) and other antioxidant compounds scavenge free radicals and delay oxidation of molecules. While antioxidant defense mechanisms inhibit damage generation, DNA repair enzymes (glycosylases) remove DNA base modifications generated by ROS. One of the most abundant DNA lesions resulting from reaction of ROS with DNA is 7,8-dihydro-8-oxo-2'-deoxyguanosine (8oxo-dG), a modification caused by hydroxylation of the $\mathrm{C}-8$ position of guanine [17-20]. It causes a $\mathrm{G} \rightarrow \mathrm{T}$ transversion because of its mispairing with adenine [21]. Increases of 8oxo-dG with age have been observed by several groups, e.g. in rats and human brain [22, 23].

A down-regulation of antioxidative protective mechanisms as well as an increased production of ROS might be important factors for an age-related increase of oxidative damages. Studies on murine aging have shown that the activity of SOD1 rose during aging in all organs studied, whereas the activities of GPx1 and CAT displayed organ-specific profiles [24]. Despite evidence for altered oxidative stress 
levels and antioxidative enzyme activities with aging [25-31], there are only few data on the relationship between DNA damage and these parameters in healthy elderly people. Therefore, the objective of this study was to test the hypothesis that biological processes of aging are associated in humans with an increase of oxidative stress and a decrease of both antioxidative capacity and DNA repair mechanisms. For the first time, the complex method of alkaline elution was applied to healthy elderly for determining oxidative DNA damage.

\section{SUBJECTS AND METHODOLOGY}

\section{Subjects}

In a cross-sectional study design, 20 healthy younger adults (10 males, 10 females, age $24-28$ years, mean age 25.8 years) were compared to 20 free-living healthy older adults (10 males, 10 females, 62-79 years, mean age 69.2 years) with respect to their oxidative status (serum peroxide level), oxidative DNA damage, antioxidative enzyme activities (SOD and GPx), total glutathione, and antioxidative micronutrients ( $\beta$-carotene, vitamin $C$, and zinc). Since disease may influence plasma antioxidant measurements, exclusion criteria were the presence of inflammatory processes as well as acute and chronic diseases. Because nutrition and life style-related parameters may also influence antioxidative parameters, they were additionally assessed by questionnaire. The study protocol was approved by the Ethics Committee of the Medical Association of Rhineland-Palatinate, Germany. All volunteers signed written informed consent forms before entering the study.

\section{Biochemical Methods}

After an overnight fast, $30 \mathrm{ml}$ peripheral venous blood was taken in the morning from each subject by a physician at the Department of Sports Medicine, University of Mainz. All blood samples of a subject were taken on the same day and analyzed within two days.

\section{Oxidative DNA Damage}

The level of oxidative DNA damage in blood lymphocytes was measured by the alkaline elution technique. The assay originally described by Kohn et al. [32] makes use of the fact that the elution rate of mammalian DNA from a membrane filter depends on the average length of the DNA molecules and therefore, the number of DNA single-strand breaks. Several other DNA modifications can be quantified with the same sensitivity, since they can be converted into single-strand breaks by a preincubation of the DNA with suitable repair enzymes. In this study, formamidopyrimidine $\mathrm{N}$-glycosylase (Fpg), the bacterial functional homolog of the mammalian repair glycosylase OGG1, was used to quantify its substrate modifications (Fpg-sensitive modifications), which include 8-oxo-dG, formamidopyrimidines and sites of base loss (AP sites) [33]. The assay was carried out as described previously [34, 35]. In brief, $8 \mathrm{ml}$ human venous blood was collected in citrate-containing syringes (BD vacutainer, $\mathrm{CPT}^{\mathrm{TM}}$ cell preparation tube, sodium citrate gel and density gradient media, Becton Dickinson, Heidelberg). Lymphocytes were isolated by centrifugation. For the analysis, $10^{6}$ cells were lyzed on a membrane filter $(25 \mathrm{~mm}$ diameter) and incubated for $50 \mathrm{~min}$ at $37^{\circ} \mathrm{C}$ with Fpg protein
(1 $\mu \mathrm{g} / \mathrm{ml}$ ) or buffer alone immediately before elution from the filter. The numbers of modifications sensitive to the repair glycosylase Fpg were obtained by subtraction of the number of single-strand breaks (SSB) observed in experiments without glycosylase treatment. Elution curves obtained with $\gamma$-irradiated cells were used for calibration, assuming that 6 Gy generated 1 single-strand break per $10^{6} \mathrm{bp}$.

\section{Oxidative Status}

As a marker for oxidative stress, the level of lipid peroxides (PerOx, Immundiagnostic, Bensheim, Germany) was determined. Lipid peroxides are assumed to result from reactions of lipids with free radicals. The test is based on the reaction of horseradish peroxidase with serum peroxides using tetramethylbenzidine (TMB) as a chromogen substrate (450 $\mathrm{nm}$ wavelength). In brief, $2.5 \mathrm{ml}$ blood was coagulated for 30 minutes at room temperature, centrifuged at $3000 \mathrm{upm}$ for $10-15$ minutes and serum was frozen at $-20^{\circ} \mathrm{C}$. $10 \mu \mathrm{l}$ of subject's serum and of calibrators were pipetted into a 96 well microplate and $100 \mu \mathrm{l}$ reaction buffer was added. Optical density of the samples was measured at $450 \mathrm{~nm}$ in an ELISA reader. $100 \mu \mathrm{l}$ reaction buffer mixture was added, followed by incubation at $37^{\circ} \mathrm{C}$. Afterwards, $50 \mu \mathrm{l}$ of stop solution was added. Subsequently, the second measurement of optical density of the sample was performed at $450 \mathrm{~nm}$. The difference between first and second measurement was proportional to the peroxide content of the sample.

\section{Antioxidative Enzymes}

\section{Superoxide Dismutase (SOD)}

Superoxide dismutase (SOD) activity was measured photometrically using the colorimetric assay kit of Randox laboratories (Krefeld, Germany, kit no. SOD125). The principle of the test is based on the method of Woolliams et al. [36]. $500 \mu \mathrm{l}$ whole blood supplemented with EDTA was used, from which cells were isolated by centrifugation and lyzed by a hypotonic buffer. The quantification method uses xanthine and xanthine oxidase to generate superoxide radicals. The superoxide anions react with 2-(4-iodophenyl)-3-(4nitrophenol)-5-phenyltretazolium chloride (INT) to form a red formazan dye. The SOD in the donor's blood sample competes with INT for superoxide radicals and thereby inhibits the production of the formazan dye. The degree of inhibition corresponds to the activity of SOD. Mean precision is $858.2 \mathrm{U} / \mathrm{g} \mathrm{Hb}$ with a coefficient of variation $(\mathrm{CV})$ of $12.2 \%$.

\section{Glutathione Peroxidase (GPx)}

Glutathione peroxidase (GPx) activity was measured by photometry using the colorimetric assay kit of Randox laboratory (Krefeld, Germany, kit no. RS505). $50 \mu$ l EDTA whole blood was used, in which cells were lyzed by addition of a hypotonic buffer. The principle of the test is based on the method of Paglia and Valentine [37]. GSH peroxidase catalyzes the oxidation of GSH by cumene hydroperoxide. In the presence of GSH reductase and NADPH, the oxidized GSH is converted to the reduced form accompanied by the oxidation of NADPH to NADP. At $340 \mathrm{~nm}$ wavelength, the decrease in absorbance is measured. The activity of GPX is assessed from the decrease in absorption at $340 \mathrm{~nm}$ wavelength due to oxidation of NADPH to NADP ${ }^{+}$. Mean precision is $43.9 \mathrm{U} / \mathrm{g} \mathrm{Hb}$; the $\mathrm{CV}$ is $5.6 \%$. 


\section{Total Glutathione}

Total glutathione (reduced and oxidized glutathione, GSH and GSSG) was measured photometrically by the method of the Medizinisches Labor (Bremen, Germany) as described in Richie et al. [38]. The principle is that reduced glutathione is oxidized to GSSG, which reacts with 5,5'dithio-bis-(2-nitrobenzoe acid). Briefly, $2.7 \mathrm{ml}$ frozen EDTA whole blood was used and samples were deproteinized by the addition of metaphosphoric acid (MPA). After protein precipitation, 5,5'-dithiobis-(2-nitrobenzoic acid) and glutathione oxidoreductase solution were added. The reaction was started by adding NADPH solution and the rate of color change was measured at $410 \mathrm{~nm}$ wavelength. Mean precision $(\mathrm{n}=9)$ is $243.7 \mathrm{mg} / \mathrm{L}$; coefficient of variation is $2.6 \%$.

\section{Antioxidative Micronutrients}

\section{Vitamin C}

Vitamin $C(\mu \mathrm{mol} / \mathrm{L})$ was determined in plasma using the reagent kit-no. 65000 of Chromsystems (München, Germany) for HPLC analysis. Interfering components were removed by means of protein precipitation. For accurate quantification, a stable internal standard was used. In brief, the precipitation reagent was reconstituted with $1.5 \mathrm{ml}$ internal standard. $100 \mu \mathrm{l}$ of the precipitation reagent was pipetted into a reaction vial. $100 \mu \mathrm{l}$ plasma was added. After incubation for 10 min at $4{ }^{\circ} \mathrm{C}$ and centrifugation for $5 \mathrm{~min}$ at 13000 rpm, $20 \mu \mathrm{l}$ of the supernatant was injected into the HPLC system. Intra-assay CV was $<3 \%$ and inter-assay CV $<5 \%$.

\section{Beta Carotene}

Beta carotene $(\mu \mathrm{mol} / \mathrm{L})$ was determined in serum using the reagent kit-no. 32000 of Chromsystems (München, Germany) for HPLC analysis. The sample was cleaned up by fast precipitation and extraction steps. In brief, $2.5 \mathrm{ml}$ blood was coagulated for 30 minutes at room temperature, centrifuged at $3000 \mathrm{rpm}$ for 10-15 minutes and aluminium foil was wrapped around. $100 \mu \mathrm{l}$ serum was pipetted into a light protected reaction vial. $50 \mu 1$ internal standard was added and mixed. $50 \mu \mathrm{l}$ precipitation reagent was added and afterwards $200 \mu \mathrm{l}$ extraction buffer. After centrifugation for $10 \mathrm{~min}$ at $13000 \mathrm{rpm}$, the supernatant was transferred into a light protected autosampler vial and $50 \mu \mathrm{l}$ was injected into the HPLC system. Beta carotene was measured after extraction and HPLC separation at $460 \mathrm{~nm}$ wavelength. The analyte was quantified by the inclusion of an internal standard, which is a non-natural occurring carotenoid-derivative, so that a single detection wavelength is required. Intra- and inter-assay $\mathrm{CV}$ is $<5 \%$.

\section{$\underline{\text { Zinc }}$}

Zinc $(\mu \mathrm{mol} / \mathrm{L})$ was measured by atomic absorption spectrometry (AAS). $2.5 \mathrm{ml}$ blood was coagulated for $30 \mathrm{~min}$ at room temperature, centrifuged at $3000 \mathrm{rpm}$ for $10-15 \mathrm{~min}$. $500 \mu \mathrm{l}$ serum was deproteinized with TCA and was subjected to atomic absorption spectrophotometry. The concentration of zinc in the sample was computed from the calibration curves. Intra- and inter-assay CV is $<5 \%$.

\section{Analysis of Nutritional and Life Style-Related Parameters}

The assessment of nutritional and life style-related parameters was considered for the past two month prior to col- lection of blood samples. Subjects completed a questionnaire with respect to their smoking habits, alcohol consumption, physical activity level, and nutritional habits. Smoking habits were coded as 1, 2 or 3 corresponding to non-smokers, past smokers, or current smokers, respectively. In the case of smokers, the number of cigarettes per week was noted. With respect to alcohol consumption, weekly consumption of wine, separately for red and white wine, was questioned (number of glasses). The physical activity level was determined considering the hours of activity per week. Moderate and medium physical activity level was defined as performing intense exercise up to seven hours per week. For those subjects, who took their dogs out for a walk at a low space, up to fourteen hours per week were defined as moderate to medium physical activity. Exhaustive physical activity was defined as performing eight and more hours of intense exercise per week.

\section{Statistical Analysis}

All statistical analyses were carried out using the SPSS/PC for Windows statistical software package release 11.0 (SPSS Inc., Chicago). Data were tested for normal distribution using the Kolmogorov-Smirnov test. Levene's test was applied to analyze homogeneity of variances. Data were given as mean and standard deviation (SD). Comparisons between age groups and between sexes were performed with t-tests for independent samples. Pearson correlation coefficients were calculated to analyze relationships between biochemical parameters. For all analyses, a two-tailed $p<0.05$ was taken as statistically significant.

\section{RESULTS}

\section{Reproducibility and Intraindividual Variability of Oxi- dative DNA Damage Measures}

Prior to the analysis of intergroup differences in oxidative DNA damage, reproducibility and intraindividual variability of the determinations were assessed (Fig. 1). The reproducibility of the quantification of Fpg-sensitive DNA modifications per $10^{6}$ bp was tested by analying two independent blood samples that were taken immediately after one another from the donor. Results show that the second measurements varied between $77 \%$ and $118 \%$ of first measurement (mean \pm S.D., $101 \pm 16 \% ; n=5$ subjects). The intraindividual variability of Fpg-sensitive DNA modifications per $10^{6} \mathrm{bp}$ was measured in seven subjects. Blood samples were taken at two different days (time interval ranging from 7 to 93 days, mean 44 days). The second measurement was between $76 \%$ and $238 \%$ of the first measurement (mean \pm S.D.: $147 \pm 67 \%$ ). There was no relationship between the absolute difference between both measurements and the time interval between taking the blood samples.

\section{Differences Between Younger and Older Subjects}

The comparative analysis of healthy younger and older subjects showed a tendency towards higher levels of DNA single-strand breaks $(\mathrm{SSB})$ in older subjects $(\mathrm{SSB}, \mathrm{p}=0.085)$ (Fig. 2). Also, a higher level of serum peroxides ("oxidative status") was observed in older men (Table 1), but findings did not reach statistical significance. With respect to the antioxidative enzymatic defense system, the SOD activity was slightly, but not statistically significantly, reduced in older 
subjects. The GPx activity was significantly increased in older males ( $\mathrm{p}<0.05$ ), but not in older females, compared to younger subjects. The SOD/GPx ratio, indicative of the relative rates of the first and second steps of antioxidative enzyme defense, was lower in older men than younger ones (Fig. 3). Older men displayed higher GSH-GSSG activities than younger ones, whereas women showed no age group differences. Regarding exogenous non-enzymatic antioxidative substances, the plasma concentration of vitamin $\mathrm{C}$ was similar in older and younger subjects, whereas intake of Bcarotene has a tendency $(\mathrm{p}=0.090)$ to be higher in elderly females (Table 1). Also, serum concentrations of zinc were higher in older women. The degree of physical activity was higher in older men and women than in younger ones, but group differences were statistically non-significant (Table $\mathbf{1}$ ).

\section{A}

\section{Fpg mod/106 bp}

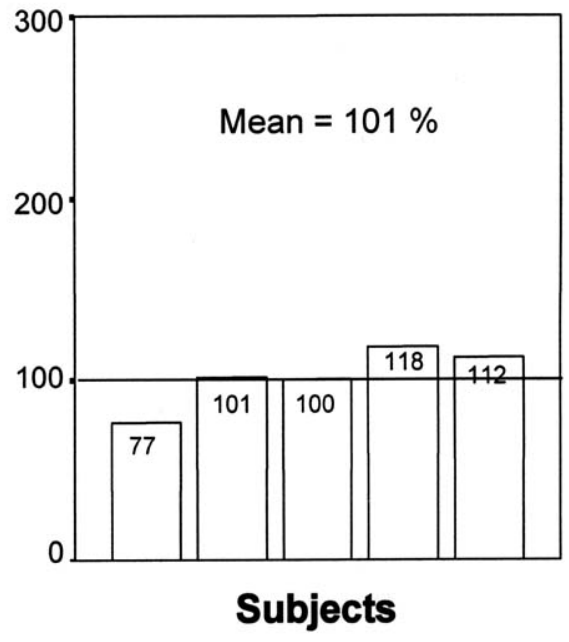

B

\section{Fpg $\bmod / 10^{6}$ bp}

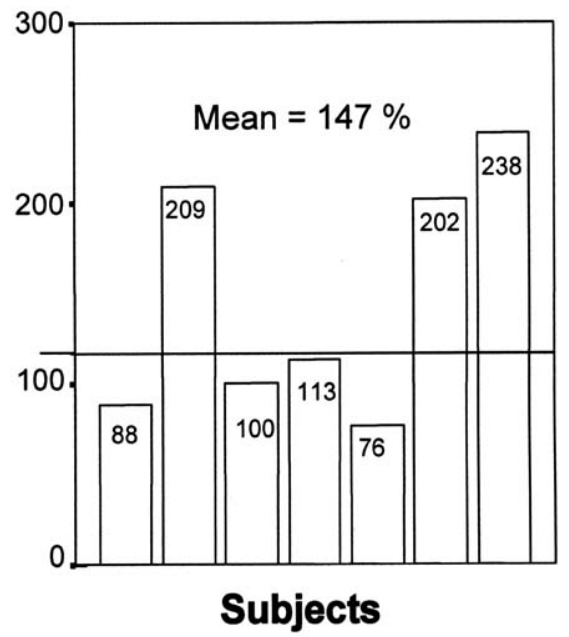

Fig. (1). Reproducibility (panel A) and intraindividual variability (B) of Fpg-sensitive DNA modifications (Fpg mod/10 6 bp). In each panel, the second measurement value is given as a percentage of the first measurement by subject.

\section{Mean $/ 10^{6}$ bp}

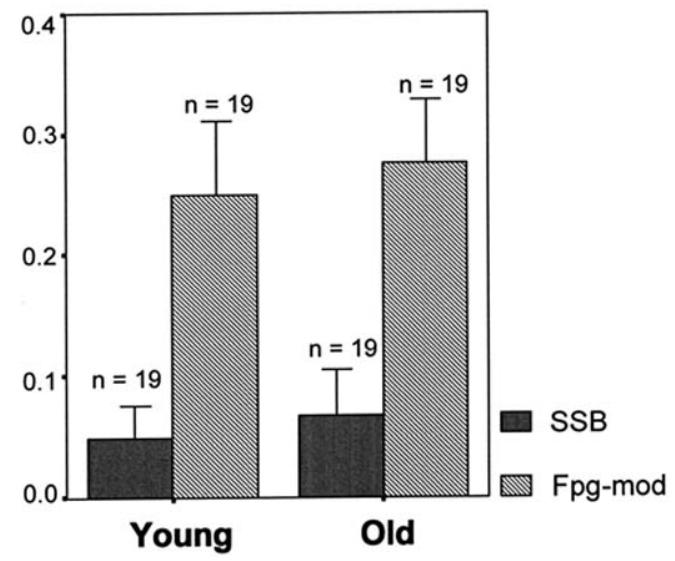

Fig. (2). Steady-state levels of single strand breaks (SSB) and Fpgsensitive DNA modifications (Fpg-mod) in lymphocytes from 19 young (24-28 yrs) and 19 old human donors (62-79 yrs). Males and females are pooled, because sex differences are not statistically significant. Older subjects show a trendency towards higher levels of oxidative DNA damage (n.s.). Columns represent means from 19 subjects \pm standard deviations. SSB, young versus old, $\mathrm{p}=0.085$; Fpg-mod, young versus old, $\mathrm{p}=0.246$.
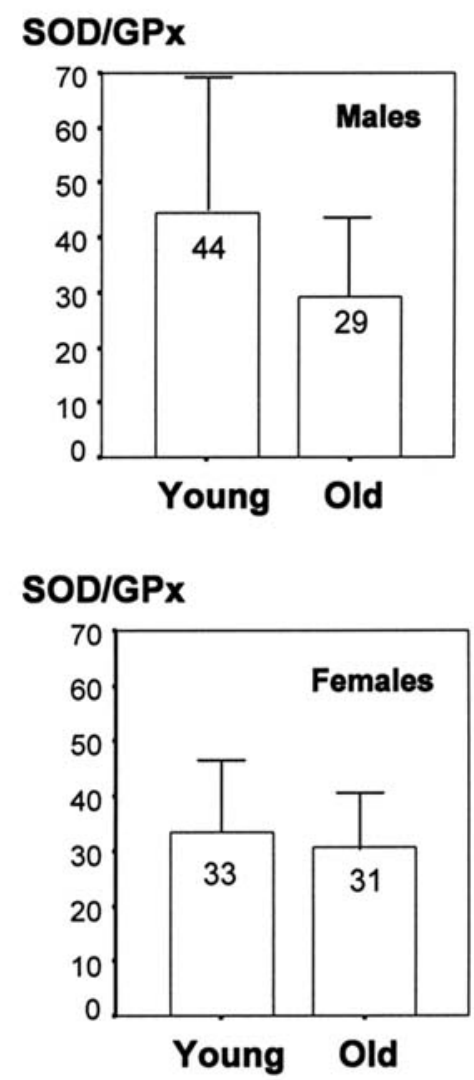

Fig. (3). Ratios of superoxide dismutase (SOD) activity (U/g Hb) and glutathione peroxidase (GPx) activity (U/g Hb) in whole blood samples of old and young male and female subjects. Older men show a tendency towards lowered SOD/GPx ratio (young versus old subjects: men, $\mathrm{p}=0.097$; women, $\mathrm{p}=0.664$ ). 
Table 1. Oxidative DNA Damage, Oxidative Status, Levels of Antioxidative Enzymes, and Degree of Physical Activity in 40 Healthy Younger and Older Adults

\begin{tabular}{|c|c|c|c|c|c|c|c|c|c|c|c|c|}
\hline \multirow[t]{2}{*}{ Character } & \multicolumn{2}{|c|}{ Young $(\mathrm{n}=\mathbf{1 0})$} & \multicolumn{2}{|c|}{ Old $(n=10)$} & \multirow{2}{*}{$t^{a}$} & \multirow{2}{*}{$\mathbf{p}$} & \multicolumn{2}{|c|}{ Young $(\mathrm{n}=\mathbf{1 0})$} & \multicolumn{2}{|c|}{ Old $(n=10)$} & \multirow{2}{*}{$t^{a}$} & \multirow{2}{*}{$\mathbf{p}$} \\
\hline & Mean & SD & Mean & SD & & & Mean & SD & Mean & SD & & \\
\hline \multicolumn{13}{|l|}{ Oxidative DNA Damage } \\
\hline Fpg mod $/ 10^{6} \mathrm{bp}$ & 0.242 & 0.089 & 0.276 & 0.080 & -0.87 & 0.394 & 0.256 & 0.058 & 0.273 & 0.056 & -0.79 & 0.441 \\
\hline \multicolumn{13}{|l|}{ Oxidative Status } \\
\hline Serum peroxides $(\mu \mathrm{mol} / \mathrm{L})$ & 38.2 & 37.7 & 59.7 & 37.3 & -1.28 & 0.216 & 390.0 & 325.3 & 131.1 & 111.5 & 2.38 & 0.036 \\
\hline \multicolumn{13}{|l|}{ Antioxidative Enzymes and Glutathione } \\
\hline SOD/GPx ratio & 44.5 & 25.3 & 29.1 & 11.4 & 1.75 & 0.097 & 33.4 & 15.7 & 30.7 & 10.8 & 0.44 & 0.664 \\
\hline \multicolumn{13}{|l|}{ Antioxidative Micronutrients } \\
\hline Vitamine $C(\mu \mathrm{mol} / \mathrm{L})$ & 11.5 & 3.3 & 11.8 & 3.9 & -0.18 & 0.856 & 14.2 & 7.6 & 13.5 & 2.6 & 0.28 & 0.785 \\
\hline$\beta$-carotene $(\mu \mathrm{mol} / \mathrm{L})$ & 433.0 & 368.4 & 586.3 & 574.0 & -0.71 & 0.486 & 412.0 & 238.3 & 710.7 & 470.3 & -1.79 & 0.090 \\
\hline $\operatorname{Zinc}(\mu \mathrm{mol} / \mathrm{L})$ & 89.3 & 7.6 & 86.8 & 16.5 & 0.44 & 0.668 & 72.1 & 12.0 & 87.5 & 12.7 & -2.78 & 0.012 \\
\hline Level of Physical Activity (hours/week) & 4.70 & 2.39 & 6.45 & 3.16 & -1.40 & 0.180 & 2.92 & 2.40 & 5.73 & 3.92 & -2.07 & 0.052 \\
\hline
\end{tabular}

Abbreviations: Fpg mod $/ 10^{6}$ bp; Fpg sensitive DNA modifications/ $10^{6}$ base pairs; GPx, Glutathione peroxidase; SD, standard deviation; SOD, superoxide dismutase; SSB/10 bp, single strand breaks/ $10^{6}$ base pairs.

${ }^{\mathrm{a}}$ Two-tailed $t$-test for independent samples.

\section{Relationships Among Biochemical Parameters}

The oxidative status did not correlate with the numbers of SSB per $10^{6} \mathrm{bp}(\mathrm{r}=0.011, \mathrm{p}=0.951)$ or Fpg-sensitive modifications per $10^{6} \mathrm{bp}(\mathrm{r}=-0.002, \mathrm{p}=0.990)$. The level of oxidative DNA damage inversely correlated with the SOD activities (Fig. 4), but showed no relationship with GSH-GSSG or GPx activities. The level of oxidative DNA damage (Fpgsensitive modifications per $10^{6} \mathrm{bp}$ ) negatively correlated with the SOD/GPx ratio in both sexes, being statistically significant in men $(\mathrm{r}=-0.50, \mathrm{p}=0.031)$, but not in women $(\mathrm{r}=-0.17, \mathrm{p}=0.528)$ (Fig. 5). The oxidative status level negatively correlated with total glutathione $(\mathrm{r}=-0.32, \mathrm{p}=$ 0.048 ), but displayed no statistically significant relationship with SOD or GPx activities. The glutathione levels and GPx activities were positively correlated with each other $(\mathrm{r}=$ $0.39, \mathrm{p}=0.013)$. Both the oxidative status and oxidative DNA damage did not show any significant relationship with plasma levels of vitamin C, $\beta$-carotene, or zinc.

\section{Relationships Between Biochemical and Lifestyle Pa- rameters}

Neither physical activity level nor smoking behavior was associated with the oxidative status, oxidative DNA damage, or antioxidant enzyme activities. Subjects drinking at least one glass of red wine every week displayed lower numbers for the oxidative status than abstinent subjects $(106.1 \pm 107.3$ versus $214.2 \pm 298.8 \mu \mathrm{mol} / \mathrm{L} ; \mathrm{t}=1.46, \mathrm{p}=0.160, \mathrm{n}=40)$, but did not differ in their levels of oxidative DNA damage $(0.26$ \pm 0.086 versus $0.26 \pm 0.045 \mathrm{Fpg}$-sensitive modifications per $\left.10^{6} \mathrm{bp} ; \mathrm{t}=-0.19, \mathrm{p}=0.851, \mathrm{n}=36\right)$.

\section{Fpg $\mathrm{mod} / 10^{6} \mathrm{bp}$}

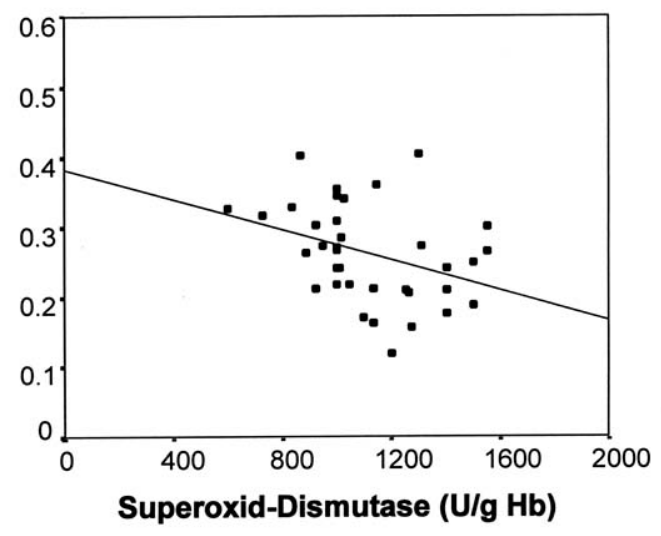

Fig. (4). Relationship between oxidative DNA damage (Fpgsensitive modifications $/ 10^{6} \mathrm{bp}$ ) and superoxide dismutase activity (SOD) in healthy subjects $(\mathrm{r}=-0.36, \mathrm{p}=0.031)$. Fpg-mod: Fpgsensitive modifications. 


\section{Fpg mod/106 bp}

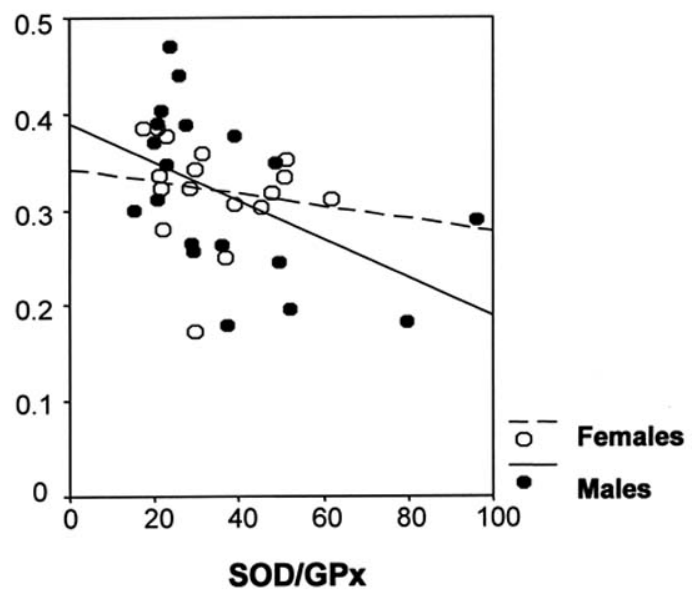

Fig. (5). Relationship between oxidative DNA damage (Fpgsensitive modifications $/ 10^{6} \mathrm{bp}$ ) and SOD/GPx ratio in healthy subjects (men: $r=-0.50, p=0.031$; women: $r=-0.17, p=0.528$ ). Fpgmod: Fpg-sensitive modifications.

\section{DISCUSSION}

We examined the hypothesis that during natural aging, the oxidative stress increases, resulting in higher levels of oxidative DNA damage in the nucleus. The comparative analysis of older and younger healthy adults showed in agreement with our hypothesis, a tendency for higher levels of SSB and Fpg-sensitive modifications, which include 8oxo-dG, in older subjects, particularly in males. This is to our knowledge, the first study which investigated 8-oxo-dG damage in healthy elderly people using alkaline elution. Our observation confirms those of Barnett and King [39], who noted higher levels of DNA damage in older subjects by analyzing single-stranded DNA. Likewise, Dušinská et al. [40] found increased DNA damage with age as well as increased repair activity of the 8-oxoguanine DNA glycosylase (OGG1). The latter observation is consistent with findings demonstrated by transcriptional profiling that aging in the human frontal cortex is associated with increased expression of OGG1 [41].

We further found that the amount of DNA damage is inversely and statistically significantly related with SOD activity. A similar relationship has been noted in the rat brain [42]. As expected, older men had higher oxidative stress levels than younger ones, as measured by serum peroxide levels (oxidative status). Likewise, other authors reported for older subjects, increased levels of oxidative stress, as assessed by measuring the malondialdehyde level (MDA), which is one end-product of the lipid peroxidation process [27, 30, 31].

The hypothesis that the antioxidative capacity is lowered in older subjects is supported by our data for SOD, but not for total glutathione and GPx. By contrast, GPx activity was increased in older men. This is in line with findings of other studies indicating that older subjects had lowered SOD activities [25, 27, 29, 43] and increased GPx activities [27, 28, 44]. In this context, transcriptional profiling of the human frontal cortex has recently shown an increased expression of GPx with aging [41]. However, some authors observed in elderly subjects unchanged [25, 29] or decreased GPx activities $[26,31]$. A decrease of SOD with aging might be due to a lowered metabolic rate and oxygen consumption generating less ROS, and thereby a lower demand for SOD. Since decreased SOD activity could also reflect $\mathrm{Zn}$ deficiency [45], we tested the subjects for their $\mathrm{Zn}$ level. We observed no relationship between SOD activity and Zn level ( $\mathrm{p}>0.05)$.

A decrease of SOD and an increase of GPx with aging might result in an imbalance in the antioxidative enzymatic defense system (in particular elevated levels of superoxide radicals). There is an evidence that a biological optimum exists for the ratio between SOD and GPx+CAT activities, which might be more relevant than the absolute activities of the enzymes themselves [46]. It has further been postulated that an altered SOD-to-(GPX+CAT) ratio affects gene expression by affecting the binding and/or availability of transcription factors to DNA [46]. We found that the SOD/GPx ratio was lowered, but not statistically significant, in older males compared to younger ones. Interestingly, we observed that subjects with lowered SOD/GPx ratio had increased oxidative DNA damage, as indicated by the level of Fpg sensitive DNA modifications. In line with this finding, studies on murine aging showed that alterations in this ratio correlated with free racial mediated cell damage as measured by lipid peroxidation. In contrast, no increased lipid peroxidation was detected in those organs where the SOD/GPX ratio was maintained during aging [24]. Furthermore, patients with Down syndrome had an altered SOD/GPx ratio, which is supposed to play a role in premature aging of this group $[46,47]$.

The oxidative status and oxidative DNA damage were not significantly affected by the plasma levels of vitamin $\mathrm{C}$, $\beta$-carotene, or zinc. This confirms other studies, which did not find a relationship between oxidative DNA damage and vitamin $C$ or $B$-carotene $[48,49]$. In the present study, the younger subjects were not significantly higher in antioxidant supplements than the aged group. Both groups did not differ significantly in their plasma levels of vitamin $C$, B-carotene, and zinc, except for higher zinc levels in older women. In contrast, other authors reported decreased plasma levels of vitamin $\mathrm{C}$ with aging [50]. This can be explained by insufficient dietary intake of this vitamin by elderly persons, because the plasma levels of vitamin $\mathrm{C}$ are correlated with dietary intake [51]. With respect to $B$-carotene levels, conflicting results have been published. Compared to healthy younger adults, institutionalized elderly displayed lowered levels of $B$-carotene [52]. Considering the age-related decrease of activities of antioxidant enzymes, a sufficient supply of dietary oxidants seems to be important in the aged. Regular supplementation with antioxidants using recommended doses might reduce oxidative damage, which promotes cardiovascular disease, cancer, and diabetes [53]. Supplementation with moderate levels of antioxidant vitamins also reduces exercise-induced oxidative damage [54].

Exercise status has a profound effect on oxidative stress damage. It has been shown that exhaustive exercise causes oxidative stress, whereas moderate exercise may act as an antioxidant [55]. Muscle-damaging resistance exercise influences antioxidant enzyme activity, i.e. alters SOD activity, 
elevates CAT activity, and declines GPx activity [56]. In elderly people, long-term physical activity preserves antioxidant capacity and limits oxidative damage accumulation [57]. In the present study, older and younger subjects showed moderate to medium physical activity, but not exhaustive activity. The older subjects of both sexes displayed a somewhat higher level of physical activity than younger ones, but age group differences were statistically nonsignificant. Thereby, the physical activity level of the subjects was not associated with altered oxidative stress level, oxidative DNA damage, or antioxidant enzyme activities.

Finally, some methodological aspects are worth mentioning. First, the observed large intraindividual variability of Fpg-sensitive modifications in some volunteers might be explained by the time interval between first and second measurement and by the season of data collection. The time interval between first and second measurement ranged from 7 to 93 days. Subjects with a larger time interval displayed a larger difference between both measurements. Also, subjects with the first measurement in spring/summer and the second measurement in winter time showed a larger intraindividual variability. However, the first measurements, which were used for group comparisons between age groups and sexes, were all taken in the same season (spring), thereby not influencing the results of the group comparisons. Second, the level of serum peroxidases was even ten times higher in young females than in young males and three times higher in young females than in old ones. This indicates highest oxidative status in young females. This might be attributed to the interaction between female sex hormones and the test system used for measuring the level of lipid peroxides as a marker of oxidative stress. We assume that female sex hormones, which are highest in young women, interact with the analytical test system. This assumption is supported by our observation that pregnant women (not included in the present study) showed a higher level of oxidative status than non-pregnant women. Further studies are needed, which should analyze the level of serum peroxidases in a sample of younger women before, during, and after pregnancy, using the present test system. Also, the test results should be compared with those of a second test system. The test system for oxidative status might be one limitation for the present study. Also, the sample size of the present study is small. Further studies with more volunteers are needed.

\section{CONCLUSION}

Basic insights in genetic and cellular causes of natural aging may help to influence aging processes in a positive manner. The results of the present study give evidence for a tendency towards increased DNA damage (single strand breaks) in older males. Also, oxidative stress was elevated in older males, but results did not reach statistical significance. In addition, results indicate age-related changes in the balance between the first step (SOD) and second step (GPx) of the enzymatic antioxidant defense system. The SOD/GPx ratio was found to be related to the level of oxidative DNA damage.

\section{ACKNOWLEDGEMENTS}

We are very grateful to Mrs. Reghina Coman, MD, Institute of Sports Medicine, Gutenberg University of Mainz, for taking blood samples of the volunteers. We thank all volunteers very much for taking part in this study. The study was financially supported by a Forschungsfonds grant from the Gutenberg University of Mainz.

\section{REFERENCES}

[1] Harman D. Aging: a theory based on free radical and radiation chemistry. J Gerontol 1956; 11: 298-300.

[2] Harman D. Free radicals in aging. Mol Cell Biochem 1988; 84: 155-61.

[3] Balaban RS, Nemoto S, Finkel T. Mitochondria, oxidants, and aging. Cell 2005; 120: 483-95.

[4] Holmes GE, Bernstein C, Bernstein H. Oxidative and other DNA damages as the basis of aging: A review. Mutat Res 1992; 275: 305-15.

[5] Swartz HM, Mäder K. Free radicals in aging: theories, facts, and artefacts. In: Esser K, Martin BM, Eds. Molecular aspects of aging. New York: Wiley 1995.

[6] Davies KJ. Protein damage and degradation by oxygen radicals, I. General aspects. J Biol Chem 1987; 262: 9895-901.

[7] Mead JF. Free radical mechanisms of lipid damage and consequences for cellular membranes. In: Pryor WA, Ed. Free radicals in biology. New York: Academic Press 1976; Vol. 1: pp. 51-68.

[8] Stadtman ER. Protein oxidation and aging. Science 1992; 257: 1220-4.

[9] Dubey A, Forster MJ, Lal H, Sohal RS. Effect of age and caloric intake on protein oxidation in different brain regions and on behavioral functions of the mouse. Arch Biochem Biophys 1996; 333: 189-97.

[10] Hamilton ML, Van Remmen H, Drake JA, et al. Does oxidative damage to DNA increase with age? Proc Natl Acad Sci USA 2001; 98: 10469-74.

[11] Ashok BT, Ali R. The aging paradox: the free radical theory of aging. Exp Gerontol 1999; 34: 293-303.

[12] Kawanishi S, Hiraku Y, Oikawa S. Mechanism of guanine-specific DNA damage by oxidative stress and its role in carcinogenesis and aging. Mutat Res 2001; 488: 65-76.

[13] Martinet W, Knaapen MWM, De Meyer GRY, Herman AG, Kockx MM. Elevated levels of oxidative DNA damage and DNA repair enzymes in human atherosclerotic plaques. Circulation 2002; 106: 927-32.

[14] González Rico M, Puchades MJ, García Ramón R, Sáez G, Tormos MC, Miguel A. Effect of hemodialysis therapy on oxidative stress in patients with chronic renal failure. Nefrología 2006; 26: 218-25.

[15] Sies H. Strategies of antioxidant defence. Eur J Biochem 1993; 215: 213-9.

[16] Meister A. Metabolism and function of glutathione. In: Dolphin D, Poulson R, Avramovic O, Eds. Glutathione: chemical, biochemical, and medical aspects. Part A. New York: Wiley 1989; pp. 367-474.

[17] de Zwart LL, Meerman JH, Commandeur JN, Vermeulen NP. Biomarkers of free radical damage applications in experimental animals and in humans. Free Radic Biol Med 1999; 26: 202-26.

[18] Cadet J, Douki T, Gasparutto D, Ravanat JL. Oxidative damage to DNA: formation, measurement and biochemical features. Mutat Res 2003; 531: 5-23.

[19] Dizdaroglu M. Chemical determination of free radical-induced damage to DNA. Free Radic Biol Med 1991; 10: 225-42.

[20] Kasai H. Analysis of a form of oxidative DNA damage, 8-hydroxy2 '-deoxyguanosine, as a marker of cellular oxidative stress during carcinogenesis. Mutat Res 1997; 387: 147-63.

[21] Grollman AP, Moriya M. Mutagenesis by 8-oxoguanine: an enemy within. Trends Genet 1993; 9: 246-9.

[22] Fraga CG, Shigenaga MK, Park JW, Degan P, Ames BN. Oxidative damage to DNA during aging: 8-hydroxy2'-deoxyguanosine in rat organ DNA and urine. Proc Natl Acad Sci USA 1990; 87: 45337.

[23] Mecocci P, MacGarvey U, Kaufman AE, et al. Oxidative damage to mitochondrial DNA shows marked age-dependent increases in human brain. Ann Neurol 1993; 34: 609-16.

[24] Cristiano F, de Haan JB, Iannello RC, Kola I. Changes in the levels of enzymes which modulate the antioxidant balance occur during aging and correlate with cellular damage. Mech Ageing Dev 1995; 80: 93-105. 
[25] Andersen HR, Nielsen JB, Nielsen F, Grandjean P. Antioxidative enzyme activities in human erythrocytes. Clin Chem 1997; 43: 5628.

[26] Guemouri L, Artur Y, Herbeth B, Jeandel C, Cuny G, Siest G. Biological variability of superoxide dismutase, glutathione peroxidase, and catalase in blood. Clin Chem 1991; 37: 1932-7.

[27] Inal ME, Kanbak G, Sunal E. Antioxidant enzyme activities and malondialdehyde levels related to aging. Clin Chim Acta 2001; 305: 75-80.

[28] Kostka T, Drai J, Berthouze SE, Lacour JR, Bonnefoy M. Physical activity, aerobic capacity and selected markers of oxidative stress and the anti-oxidant defence system in healthy elderly men. Clin Physiol 2000; 20: 185-90.

[29] Pansarasa O, Castagna L, Colombi B, Vecchiet J, Felzani G, Marzatico F. Age and sex differences in human skeletal muscle: role of reactive oxygen species. Free Radic Res 2000; 33: 287-93.

[30] Rodriguez-Martinez MA, Ruiz-Torres A. Homeostasis between lipid peroxidation and antioxidant enzyme activities in healthy human aging. Mech Ageing Dev 1992; 66: 213-22.

[31] Rondanelli M, Melzi d'Eril GV, Anesi A, Ferrari E. Altered oxidative stress in healthy old subjects. Aging (Milano) 1997; 9: 221-3.

[32] Kohn KW, Erickson LC, Ewig RA, Friedman CA. Fractionation of DNA from mammalian cells by alkaline elution. Biochemistry 1976; 15: 4629-37.

[33] Dizdaroglu M. Base-excision repair of oxidative DNA damage by DNA glycosylases. Mutat Res 2005; 591: 45-59.

[34] Epe B, Hegler J. Oxidative DNA damage: endonuclease fingerprinting. Methods Enzymol 1994; 234: 122-31.

[35] Pflaum M, Will O, Epe B. Determination of steady-state levels of oxidative DNA base modifications in mammalian cells by means of repair endonucleases. Carcinogenesis 1997; 18: 2225-31.

[36] Woolliams JA, Wiener G, Anderson PH, McMurray CH. Variation in the activities of glutathione peroxidase and superoxide dismutase and in the concentration of copper in the blood in various breed crosses of sheep. Res Vet Sci 1983; 34: 253-6.

[37] Paglia DE, Valentie WN. Studies on the quantitative and qualitative characterization of erythrocyte glutathione peroxidase. J Lab Clin Med 1967; 70: 158-69.

[38] Richie JP Jr, Skowronski L, Abraham P, Leutzinger Y. Blood glutathione concentrations in a large-scale human study. Clin Chem 1996; 42: 64-70.

[39] Barnett YA, King CM. An investigation of antioxidant status, DNA repair capacity and mutation as a function of age in humans. Mutat Res 1995; 338: 115-28.

[40] Dušinská M, Džupinková Z, Wsólová L, Harrington V, Collins AR. Possible involvement of XPA in repair of oxidative DNA damage deduced from analysis of damage, repair and genotype in a human population study. Mutagenesis 2006; 21: 205-11.

[41] Lu T, Pan Y, Kao SY, et al. Gene regulation and DNA damage in the ageing human brain. Nature 2004; 429: 883-91.

[42] Cardozo-Pelaez F, Brooks PJ, Stedeford T, Song S, SanchezRamos J. DNA damage, repair, and antioxidant systems in brain regions: a correlative study. Free Rad Biol Med 2000; 28: 779-85.
[43] Andersen HR, Jeune B, Nybo H, Nielsen JB, Andersen-Ranberg K, Grandjean P. Low activity of superoxide dismutase and high activity of glutathione reductase in erythrocytes from centenarians. Age Ageing 1998; 27: 643-8.

[44] Erden-Inal M, Sunal E, Kanbak G. Age-related changes in the glutathione redox system. Cell Biochem Funct 2002; 20: 61-6.

[45] Bertger WJ, Fish TJ, O'dell BL. Effects of dietary copper and zinc erythrocyte stability and superoxide dismutase activity. Proc Soc Exp Biol Med 1979; 158: 279-82.

[46] de Haan JB, Cristiano F, Iannello RC, Kola I. Cu/Zn-superoxide dismutase and glutathione peroxidase during aging. Biochem Mol Biol Int 1995; 35: 1281-97.

[47] Groner Y, Elroy-Stein O, Avraham KB, et al. Down syndrome clinical symptoms are manifested in transfected cells and transgenic mice overexpressing the human $\mathrm{Cu} / \mathrm{Zn}$-superoxide dismutase gene. J Physiol Paris 1990; 84: 53-77.

[48] Collins AR, Gedik CM, Olmedilla B, Southon S, Bellizzi M. Oxidative DNA damage measured in human lymphocytes: large differences between sexes and between countries, and correlations with heart disease mortality rates. FASEB J 1998; 12: 1397-400.

[49] Gackowski D, Ciecierski M, Jawien A, Olinski R. Background level of 8-oxo-2'-deoxyguanosine in lymphocyte DNA does not correlate with the concentration of antioxidant vitamins in blood plasma. Acta Biochim Pol 2001; 48: 535-9.

[50] Mezzetti A, Lapenna D, Romano F, et al. Systemic oxidative stress and its relationship with age and illness. Associazione Medica Sabin. J Am Geriatr Soc 1996; 44: 823-7.

[51] Palli D, Decarli A, Russo A, et al. Plasma levels of antioxidant vitamins and cholesterol in a large population sample in CentralNorthern Italy. Eur J Nutr 1999; 38: 90-8.

[52] Morinobu T, Tamai H, Tanabe T, et al. Plasma alpha-tocopherol, beta-carotene, and retinol levels in the institutionalized elderly individuals and in young adults. Int J Vit Nutr Res 1994; 64: 104-8.

[53] Elmadfa I, Meyer AL. Body composition, changing physiological functions and nutrient requirements of the elderly. Ann Nutr Metab 2008; 52(Suppl 1): 2-5.

[54] Sureda A, Tauler P, Aguiló A, et al. Influence of an antioxidant vitamin-enriched drink on pre- and post-exercise lymphocyte antioxidant system. Ann Nutr Metab 2008; 52: 233-40.

[55] Gomez-Cabrera MC, Domenech E, Viña J. Moderate exercise is an oxidant: upregulation of antioxidant genes by training. Free Radic Biol Med 2008; 44: 126-31.

[56] Zembron-Lacny A, Ostapiuk J, Slowinska-Lisowska M, Witkowski K, Szyszka K. 2008 Pro-antioxidant ratio in healthy men exposed to muscle-damaging resistance exercise. J Physiol Biochem 2008; 64: 27-35.

[57] Simar D, Malatesta D, Badiou S, Dupuy AM, Caillaud C. Physical activity modulates heat shock protein-72 expression and limits oxidative damage accumulation in a healthy elderly population aged 60-90 years. J Gerontol A Biol Sci Med Sci 2007; 62: 1413-9. 